\title{
HET IRRIGATIE VRAAGSTUK IN SURINAME
}

\author{
DOOR
}

\section{JUNKER}

Wanneer men over irrigatie hoort spreken, zooals dit gedurende de laatste behandeling der Surinaamsche begrooting in de Tweede Kamer plaats had, denkt men onwillekeurig aan uitgestrekte oppervlakten uitgedroogd land, dat door bevloeiïng in staat moet worden gesteld den groei van cultuurgewassen mogelijk te maken. Landbouwkundigen zullen bij het hooren van het woord irrigatie niet altijd slechts aan het uiterste, voortdurend of lang aanhoudend gebrek aan water, denken, doch onder irrigatie ook verstaan den maatregel om bepaalde terreinen ten behoeve van bepaalde gewassen gedurende eenigen tijd te doen onderloopen en den waterstand op een bepaald peil te houden.

Laten wij in de eerste plaats de meteorologische toestanden in Suriname onder het oog zien en aan de hand daarvan nagaan of het werkelijk dringend noodig is om daar nieuwe gebieden voor bevloeiïng gereed te maken. Hierbij zal tevens de onuitvoerbaarheid van een plan, dat door de weersomstandigheden ongetwijfeld tot mislukking is gedoemd, ter sprake worden gebracht.

Suriname is geen waterarm land zooals Californie en andere subtropische landen, waarin men zich voornamelijk op boomcultures zooals citrus toelegt. De gemiddelde jaarlijksche regenval bedraagt $2500 \mathrm{~mm}$. Tengevolge van dezen overvloedigen regenval heerscht gedurende een groot gedeelte van het jaar in sommige door landbouwers bewoonde streken watersnood. De waterbouwkundige dienst is er tot nu toe niet in geslaagd dit te verhelpen. In het bijzonder heeft gedurende het zeer regenrijke jaar 1938 de kleine landbouw op de terreinen langs den spoorweg, voornamelijk in de omgeving van Lelydorp, waar een uitgebreide Javaansche kolonisatie aangetroffen wordt, van het overvloedige water, dat niet geloosd kon worden, te lijden gehad. Terwijl de watersnood gedurende ieder tijdperk van grooten regenval telken jare terugkeert, neemt zij niet altijd het abnormale karakter 
van het hierboven vermelde jaar aan. Dit vindt zijne oorzaak in de vrij regelmatige schommelingen van grooten regenval en lang aanhoudende droogte gedurende tijdperken van veertien à zestien jaren. Zoo kenmerkte zich het jaar 1912 door een uiterst felle droogte, en lieten de regenvallen gedurende eenige daaropvolgende jaren veel te wenschen over. Van 1918 tot en met 1922 had Suriname weder zeer regenrijke jaren, en in 1926 zette weer abnormale droogte in. Daarna volgden eenige jaren met minder rijkelijke regens, terwijl in 1938 weder een toppunt van grooten regenval bereikt werd.

In het algemeen echter heeft Suriname een vrij regelmatigen regenval. De commissie van het Suriname Studie Syndicaat vermeldt dit ook in haar rapport. Op blz. 17 daarvan lezen wij: „Over het algemeen is de kuststrook zeer regenrijk; dat men het binnenland ingaande lager regenval zou vinden, wordt door de verkregen cijfers niet bevestigd.

Het ligt voor de hand, dat deze vrij goed over het jaar verdeelde regenval met de hooge temperatuur en den bijzonder vruchtbaren bodem de groeivoorwaarden voor de planten in Suriname buitengewoon gunstig maken".

Aan dezen regenval, in het bijzonder aan de periode van zeer rijke regens, den grooten regentijd, heeft zich de rijstcultuur op zeer goede wijze aangepast. Omdat deze aanpassing ook rekening houdt met de werkindeeling van den kleinen landbouwer in het algemeen, zou een verstoren der eenmaal gevonden orde slechts nadeelige gevolgen met zich medebrengen.

Tot nu hebben wij het alleen over den regenval gehad. Deze heeft hier niet, zooals dit in de gematigde zônen der aarde het geval is, op onregelmatige tijdstippen van het jaar plaats, doch is aan bepaalde seizoenen gebonden. In Suriname kent men vier jaargetijden, die elkaar vrij regelmatig afwisselen, een regelmatigheid, welke slechts door de hierboven vermelde perioden om de 14 à 16 jaren eenigszins verstoord wordt. De benaming der seizoenen: kleine en groote regentijd en kleine en groote droge tijd maken den toestand duidelijk.

De gedurende de regenseizoenen in de rivieren, kreeken en moerassen verzamelde enorme watermassa verdwijnt gedurende de perioden van droogte. Tengevolge hiervan droogt het land in het alluviale gebied der kolonie geheel en al uit. Dit geldt ook voor de laaggelegen kleigronden van het zee-rivieralluvium en de Savannah.

Gedurende de perioden van abnormale droogte is deze uit- 
droging volkomen. Dit blijkt duidelijk uit de in het gebied buiten den polder voorkomende boschbranden. Zoowel in 1912 als in 1926 zijn honderdduizende hectaren bosch door het vuur vernield. Het waren uitsluitend zwampbosschen, die ten prooi aan de vlammen vielen. Hiermede is voldoende aangetoond, dat op waterreservoirs voor eventueele irrigatie in het lage land niet gerekend kan worden. Niet veel beter is het met de water aanvoerende rivieren gesteld. In de eerste plaats moet opgemerkt worden, dat eb en vloed zich bijv. aan de Surinamerivier tot $100 \mathrm{~km}$ het binnenland in doen gevoelen, en dat gedurende de springgetijden de vloedgolf krachtig opstuwt. Tengevolge hiervan verzouten de rivieren over een groote lengte van haar loopen van zee uit. Zoo moest in 1926 drinkwater voor Paramaribo en Ketelwater voor de plantage Marienburg, die aan de Commewijne is gelegen, op meer dan zestig kilometer afstand van de kust uit de Surinamerivier gepompt worden. Ook is de waterstand gedurende lang aanhoudende droogte in de rivieren zeer laag; de bovenrivieren loopen zelfs nagenoeg droog en zouden dit vermoedelijk geheel en al doen, wanneer de talrijke rotsbarrières, die gedurende den regentijd geduchte watervallen vormen, er niet waren. In ieder geval zal het voor de irrigatie benoodigde water slechts door middel van een krachtig pompstation uit de waterarme rivier in het kanaal, dat voor de aanvoer zal moeten worden aangelegd, gebracht kunnen worden.

Op welke wijze de lagere Surinaamsche gronden uitdrogen is in het najaar 1939 gebleken. Het aan den noordrand der Savannah gelegen pompstation der waterleiding van Paramaribo kon gedurende den drogen tijd niet voldoende water leveren, omdat de aanwezige watervoorraad weggeslonken was.

In tegenstelling tot het lage land droogt de bodem van het heuvelland nooit uit. De hierboven vermelde boschbranden maken als het ware halt aan den voet der heuvelen; nooit heeft het vuur de houtopstanden in het hoogere land geteisterd. Ook de insterving van bepaalde houtsoorten tengevolge van watergebrek, welke gedurende de perioden van lang aanhoudende droogte in het lage land werd waargenomen, had gedurende dezelfde perioden in het heuvelland niet plaats. Op overtuigende wijze werd het verschijnsel van een nagenoeg constant blijvend vochtigheidsgehalte van den bodem bij een citrusaanplant op de heuvels aan de Boven-Suriname aangetoond. In het midden van de maand Juli, dus bijna op het einde van den grooten regentijd, van het jaar 1935 werd een hondertal, uit den cultuurtuin te Paramaribo 
ontvangen plantjes, grapefruit en sinaasappelen, geplant. Noemenswaardige regens vielen er na het uitplanten niet meer. Het najaar kenmerkte zich door een hevige droogte, die abnormaal lang, tot tegen Kerstmis, aanhield. Desniettegenstaande groeiden de boomjes en ontwikkelden zij zich buitengewoon gunstig, geen enkele stierf. Omdat de aanplant als proefobject voor het Gouvernement diende, werden de opgedane bevindingen officiëel vastgelegd. In het verslag van het Departement van LandbouwEconomische Zaken over de jaren 1936 en 1937 lezen wij op blz. 92 onder het hoofd Proefveld in het heuvelland het volgende: „De ontwikkeling der boompjes was normaal, zoodat het toedienen van bemesting nog niet noodig werd geoordeeld. Ook bij scherpe droogte deed zich bij deze plantjes geen watergebrek voor, zoodat het voornemen om te irrigeeren door water uit de rivier te pompen, niet tot uitvoering kwam".

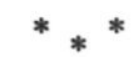

De hierboven weergegeven toestanden in het lage land van Suriname betreffen, wat van zelf spreekt, het land, dat buiten de talrijke kleine polders ligt, waarvan ieder op zichzelf eene plantage heeft uitgemaakt of nog vertegenwoordigt. Het is een gedeelte van het niet ingepolderde land, dat men voor irrigatie op het oog heeft. Daar uit de gedurende eeuwen opgedane ervaring de leering getrokken kan worden, dat in het alluviale land groote oppervlakten gedurende seizoenen, waarin behoefte aan irrigatie zal bestaan, niet bevloeid kunnen worden, omdat de daarvoor benoodigde watervoorraden gedurende perioden van droogte ten eenenmale ontbreken, zal het velen toch ongerijmd voortkomen, dat men het voornemen kan koesteren dit wel te doen. Onbegrijpelijker zal het nog worden, wanneer men weet, dat Suriname, dat het altijd van den landbouw heeft moeten hebben, een stelsel bezit, dat het vochtigheidsgehalte van den bodem en daarmede ook de bodemventilatie op nagenoeg volmaakte wijze regelt. Dit stelsel hebben wij aan het juiste inzicht van onze voorvaderen te danken. Aan den polderaanleg, die in hoofdzaak een drainagestelsel is, echter ook aan het gedurende perioden van droogte bewaard worden van het regenwater in kanalen binnen den polder, dat de elementen van irrigatie bevat, is het te danken, dat door de eeuwen heen ook de felste droogten geen ernstige schade aan de cultures berokkend hebben.

Teneinde den lezer in de gelegenheid te stellen zich van deze 
aangelegenheid een goed begrip te vormen, zullen wij alvorens verder te gaan een deskundige aanhalen. Wijlen de heer J. J. Leys, landbouwconsulent bij het voormalige Departement van Landbouw in Suriname en tijdelijk directeur van dit instituut, wijdde in het destijds verschijnend landbouwkundig tijdschrift voor Suriname en Curaçao, West-Indië, een artikel aan de bodemventilatie, waarin de begrippen van irrigatie en drainage besproken worden. In het Maartnummer van het jaar 1916 schreef hij: „Ieder, die iets afweet van den landbouw in Suriname zal toestemmen, dat het irrigatie- en drainage vraagstuk in onze kolonie van groote beteekenis is.

Irrigeeren en draineeren zijn twee werkzaamheden, die juist het tegengestelde bedoelen.

Onder irrigeeren verstaan we het land voorzien van water, 't zij door de trenzen vol te laten loopen, zooals dat hier en daar geschiedt in den drogen tijd op onze cacaoplantages, 't zij door het geheele veld onder water te zetten, zooals dat geschiedt op suikerplantages met stukken, die tijdelijk aan de cultuur worden onttrokken, of op de rijstvelden, waarop men gaarne die laag water houdt gedurende den groei van de rijstplanten.

Onder draineeren verstaat men het afvoeren van overtollig water. We zien die drainage dagelijks op de plantages, als bij ebbe de sluizen worden opengezet en het plantagewater uit trenzen en trekkers en loostrenzen, de rivieren instroomt.

Het irrigatie-vraagstuk is blijkens bovenstaande lang niet van zooveel beteekenis als het drainage-vraagstuk.

Verder lezen wij nog op bladzijde 4:

„Het is mijn bedoeling niet om in dit artikel te spreken over ons loozingssysteem.

Ik constateer alleen dit feit, dat men buiten de plantages, dus bij de kleine landbouwers, bij de Hollandsche boeren, nooit iets anders hoort, dan klagen over het slechte loozingssysteem. Niet, dat de groote droge tijd hen nooit parten speelt, zeker er wordt ook wel eens gebrek geleden aan water in den bodem, maar het meeste nadeel ondervindt men toch van te veel water.

Een goed aangelegd drainage en irrigatie-systeem moet zorgen, dat wij in den regentijd niet te veel en in den drogen tijd geen tekort aan water hebben".

Van de streken, welke in het bijzonder gedurende jaren van grooten regenval geteisterd worden, neemt het grootendeels Javaansche kolonisatiegebied langs den spoorweg de eerste plaats is. En omdat de nood hier door de verwaarloozing van het 
district soms zeer groot is, en omdat hier het gebrek aan continuiteit van het bestuursbeleid op duidelijke wijze blijkt, is de geschiedenis dezer kolonisatie vermeldenswaardig.

Reeds kort na het begin van den aanleg van den spoorweg werd het plan van Gouverneur Lely uitgevoerd, dat de kolonisatie van het gebied ten Oosten en ten Westen van de spoor ten doel had. In beide richtingen werden over eene lengte van ongeveer twintig kilometers talrijke wegen met eene gemiddelde lengte van vijf kilometers aangelegd. Het over vele jaren verdeelde werk heeft tonnen gouds verslonden. Voornamelijk hebben zich op de door het Gouvernement uitgegeven perceelen Javanen gevestigd. Reeds spoedig na de uitgifte van het land werd ernstig over de slechte loozing der terreinen geklaagd. Men heeft getracht afwatering te verkrijgen door het graven van een kanaal, het kanaal van Toutliesfaut, dat in de Surinamerivier uitmondt. Het is echter op eene mislukking uitgeloopen, het kanaal heeft nooit aan de gestelde eischen beantwoord; de toestand bleef, zooals hij was; bijna ieder jaar loopt een groot aantal perceelen onder, wordt groote schade veroorzaakt, en de malaria als het ware aangekweekt. Gedurende het grootste gedeelte van het jaar 1938 is de toestand zoo geweest, dat op sommige plaatsen zelfs de rijstaanplant schade heeft geleden; gedurende maanden stonden groote oppervlakten blank.

Zooals uit het bovenstaande blijkt, is het in het kolonisatiegebied langs den spoorweg altijd bij den aanleg der wegen gebleven. Geen der opvolgende besturen is tot den uitbouw overgegaan. Met den aanleg van polders, die als drainage- en tevens als irrigatiewerken hadden kunnen functioneeren, zouden de bij uitnemendheid gunstig gelegen terreinen tot hun recht gekomen zijn. Voornamelijk omdat de afvoer van de producten door de gunstige ligging van het land langs den spoorweg zeker is, vestigen zich daar steeds meer kolonisten, voornamelijk Javanen. Ofschoon steeds meer pachtgelden uitkomen, blijft het Gouvernement zich als een echte huisjesmelker gedragen.

Zooals de toestand nu eenmaal is (in Suriname doet men wat men wil, en in Nederland ontbreekt het juiste inzicht) lijkt het nutteloos aan deze toestanden bekendheid te geven. Het feit echter, dat in Suriname nieuwigheden op komst zijn, die m.i. veel geld zullen kosten en onnoodig zijn, en den kiem der mislukking met zich mededragen, dwingt mij tot verwondering.

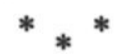


Het denkbeeld in het alluviale land van Suriname ten behoeve van den landbouw nieuwe terreinen te ontginnen en deze door de invoering door een voor de kolonie nieuw irrigatiestelsel tot ontwikkeling te brengen is van zeer jongen datum. De verwezenlijking daarvan beteekent het los laten der ervaring, het lichtzinnig aanvaarden van veronderstellingen en het betreden van het gebied der proefnemingen. Als bijkomende omstandigheid verdient vermelding, dat door het propageeren van dit denkbeeld in Nederland m.i. weder eens geheel onjuiste voorstellingen omtrent de bodemgesteldheid in de kolonie ingang hebben gevonden. Men is er hier te lande onder den indruk van gekomen, dat in Suriname uitgestrekte gebieden worden aangetroffen, die door watergebrek van geen waarde zijn, door bevloeiïng echter voor de Javaansche kolonisatie geschikt kunnen worden gemaakt. Gedurende de gesprekken, welke ik over dit onderwerp met verschillende personen hier te lande heb gevoerd, kwam telkens de voorstelling van een waterarm Suriname, van uitgestrekte oppervlakten uitgedroogd land, dat slechts door bevloeiïng voor den landbouw geschikt gemaakt kan worden, tot uiting.

De landbouw in Suriname is gedurende eeuwen wèlgevaren bij een stelsel, dat, zoowel wat de watervoorziening der cultuur aangaat, als wat den afvoer van overtollig regenwater betreft, bij uitnemendheid aan de daaraan gestelde eischen heeft beantwoord. Deskundigen hebben dit stelsel nagenoeg volmaakt genoemd. Terwijl dit vroeger slechts voor den zoogenaamden grooten landbouw, de ondernemingen of plantages toepassing heeft gevonden, is het Gouvernement ongeveer dertig jaren geleden ertoe overgegaan polders in het groot voor den rijstbouw aan te leggen en daarin kleine landbouwers, Briisch-Indiërs en Javanen, te vestigen. Deze aanleg in Nickerie is een groot succes geworden, en met dit voorbeeld voor oogen is het onbegrijpelijk, dat men voornemens kan zijn in een ander deel der kolonie in het onzekere en op veel duurder wijze proeven te gaan nemen. Want een proefneming blijft de op wateraanvoer ingestelde irrigatie. Deze zal ook altijd een ondergeschikte rol moeten blijven spelen. De waterafvoer in het alluviale land, welks terreinen zoo goed als geen verval hebben, zal altijd van grootere beteekenis zijn dan eventueele bevloeiïng. Men bedenke slechts, dat gedurende den grooten regentijd de regenval op sommige dagen $100 \mathrm{~mm}$ en meer bedraagt. In hoofdzaak zal men dus tot het oude beproefde systeem moeten terugkeeren. De met Duitsche motorenfabrieken gevoerde besprekingen wijzen er wel op, dat men zich voorstelt het overtol- 
lige regenwater op mechanische wijze te verwijderen; dit zoude echter slechts een moderniseering van het drainagestelsel beteekenen, en de vraag blijft open: Wat zal duurder komen te staan, het installeeren van pompstations of de aanleg van sluizen?

Het vooronderzoek, waaraan schrijver dezes een klein aandeel heeft gehad, wijst er alleszins op, dat de voorgenomen irrigatie werd gebouwd op de veronderstelling, dat de natuur voor groote watervoorraden, die slechts aangesproken behoefden te worden, heeft zorg gedragen. Reeds het jaar 1937 bracht in deze eene ontgoocheling, die duidelijk aantoont, op welke geringe kennis van het land het denkbeeld der irrigatie werd gegrond. Gedurende de verkenning per vliegtuig, op zoek naar natuurlijke waterreservoirs, werd ten Noorden van het Kordonpad een nieuwe rivier ontdekt. Twee eeuwen te voren hebben officieren van de toenmalige landmacht in West-Indië dat gebied opgenomen en in kaart gebracht. Van eene rivier werd geen melding gemaakt. Toen in de maand October over land naar de rivier gezocht werd, was deze verdwenen. Ook van de kreek, waarin de rivier moest uit monden, waren slechts ondiepe zwampen overgebleven.

Zooals de toestand in het gebied tusschen het stroomgebied der Suriname- en Commewijne-rivieren bij onderzoek werd vastgesteld is hij overal in Suriname.

Met den slotzin van een in het Algemeen Handelsblad op 12 October 1939 verschenen artikel over de bodemgesteldheid in Suriname besluiten wij ook dit artikel. Deze luidt: ,,Thans zal moeten worden afgewacht welken weg men wil opgaan. Nuchtere berekeningen zullen dien ongetwijfeld aanwijzen. Tegenover de exploitatie door middel van kostbare kunstwerken staat de ontginning, die ze overbodig maakt, omdat de natuur zelf voor alles heeft zorg gedragen".

Hieraan worde slechts toegevoegd, dat de laatste zin voornamelijk betrekking heeft op de reusachtige gebieden, in de beschrijving hierboven vermeld, die ieder irrigatie overbodig maken.

Paschen 1940. 